The Journal of Public Space

ISSN 2206-9658

2019 | Vol. 4 n. 3

https://www.journalpublicspace.org

\title{
Neither a hoax nor art: Politics
}

Fernanda Regaldo, Renata Marquez, Roberto Andrés, Wellington Cançado

\author{
Piseagrama \\ contato@piseagrama.org
}

\begin{abstract}
On a Saturday morning in May 2013, a sign indicating a public work was installed on Padre Belchior Street, in central Belo Horizonte. According to the sign, in just a couple of days the busy street would become a construction site in which the main goal would be to undo four asphalted lanes and bring back instead the late Leitão stream - an urban stream which four decades ago was channelled and covered with concrete, giving place to a roadway. Three days later, the sign was no longer in place and the Federal Police had begun to investigate the authors of the "fictitious project" for improper use of government logos. This article recovers this story in order to discuss the relationship between the processes that mark how cities are constructed, public participation and urban interventions.
\end{abstract}

Keywords: urban politics, urban streams, public space, urban art, participation

To cite this article:

Regaldo, F., Marquez, R. Andrés, R., Cançado, W. (2019). Neither a hoax nor art: Politics, The Journal of Public Space, 4(3), I85-191, DOI 10.32891/jps.v4i3.1217

This article has been double blind peer reviewed and accepted for publication in The Journal of Public Space. (i) This work is licensed under a Creative Commons Attribution - Non Commercial 4.0 International License https://creativecommons.org/licenses/by-nc/4.0/ 
On May 25th, 2013, a sign indicating a public work was installed on Padre Belchior Street, in central Belo Horizonte. Signs like that do not usually arouse the interest of citizens of the sixth largest city in Brazil (or of any Brazilian city at all, for that matter), who are used to being excluded from public policy and decision making concerning the spaces they inhabit.

The announced work, which consisted in the "Restoration of the Leitão Stream" (an urban stream which four decades ago was channelled and covered with concrete, giving place to a roadway), caused immediate controversy. Curious passers-by stopped in front of the buzz formed on the corner of Augusto de Lima Avenue. Some praised the project, others were surprised by the initiative and many attacked it, on different grounds. There were technical arguments (how will traffic flow?), conformist stances (these things do not work in Brazil!) and hygienist pleas (we cannot make this a place for the homeless!).

With strong opinions on the tip of their tongues, local shopkeepers and merchants argued effusively, and at last articulated a collective reaction to such an unexpected intervention. Their mobilization had a practical vein: the stream restoration could put commercial activities at risk, both during the works and after them. According to the sign, in just a couple of days their busy street would become a construction site in which the main goal would be to undo four asphalted lanes and bring back instead the late Leitão. The stream would then be protagonist of an urban renewal in which clean water, fish, benches and cycle paths would coexist with the local commerce and the social and cultural diversity of the city centre.
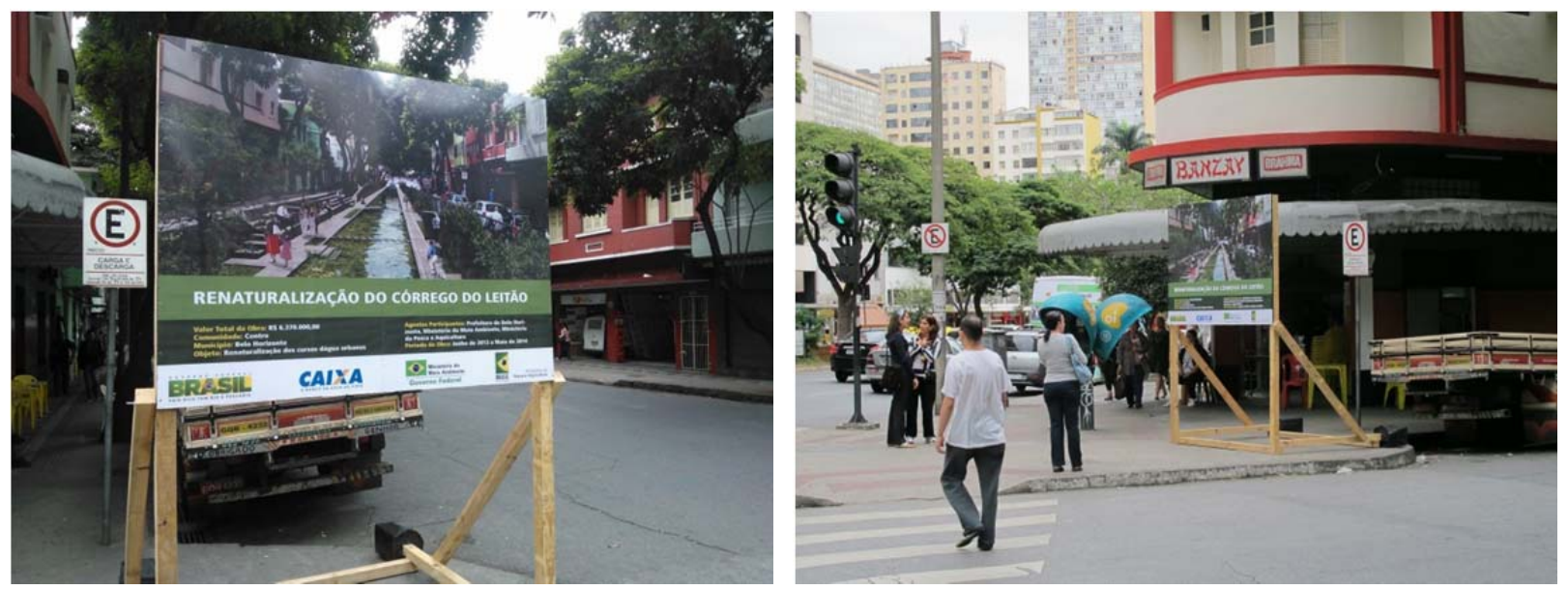

Figure I. A sign indicating a public work installed on Padre Belchior Street, in central Belo Horizonte, Brazil.

News of the unexpected utopia that the Federal Government, the City of Belo Horizonte, and the Ministries of the Environment and of Fishery and Aquaculture promised to jointly carry out with funds from the Federal Savings Bank quickly spread. On Monday, the 27th, newspaper Hoje em Dia printed a picture of the sign on its front page and devoted a full page to the report under the title "Leitão Stream Back to the Scene: Boldness or Prank?". The paper listened to residents and local traders, and it revived the memory of its readers by briefly narrating the tragic fate of Leitão in recent 
decades. It also broadened the discussion by reporting on the restoration of Cheonggyecheon river in Seoul, South Korea, about 10 years ago.
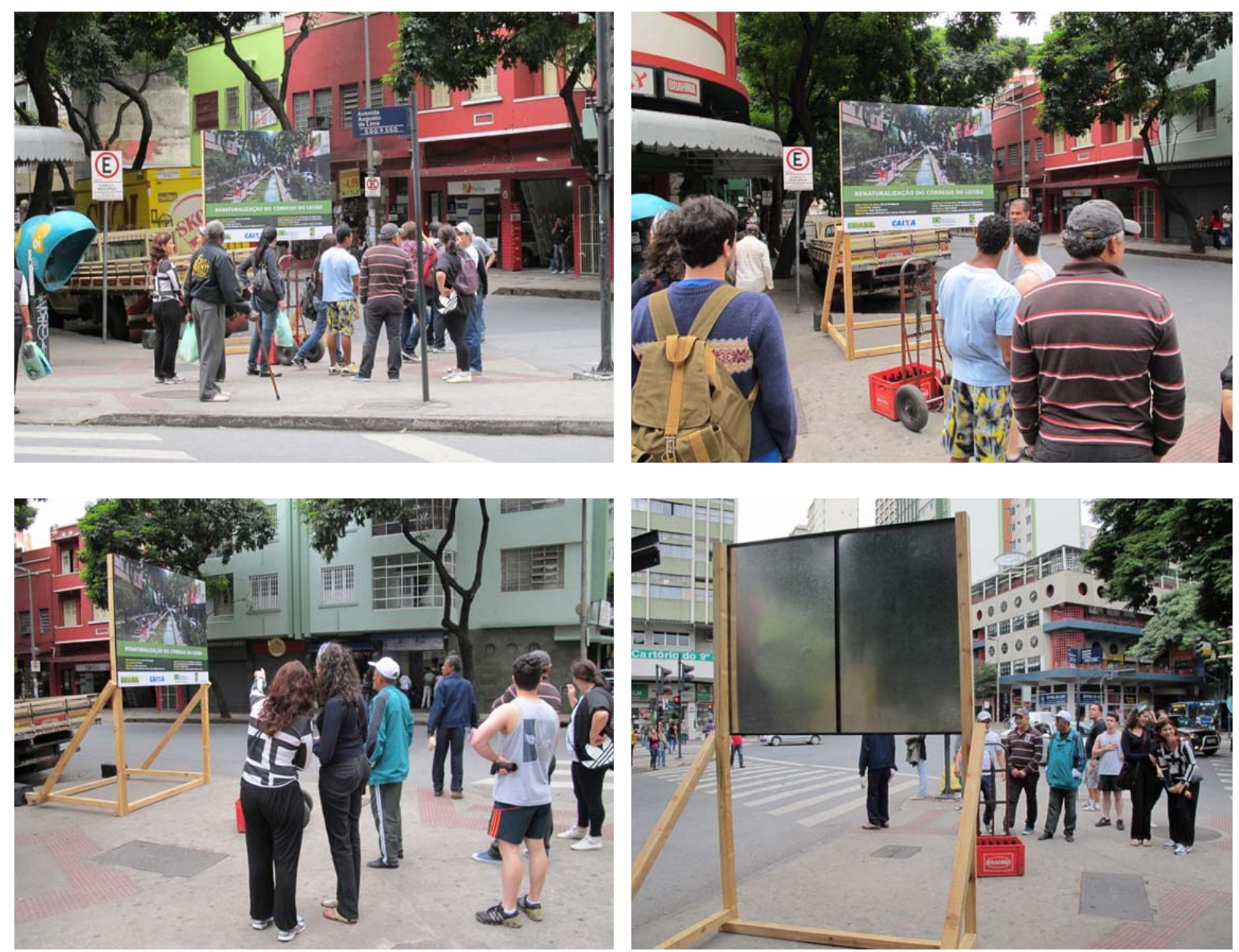

Figure 2. The interest of local residents and traders, looking at the sign.

From the papers, the news quickly bounced onto social networks. The City of Belo Horizonte, whose relentless water policy has prioritized the channelling and covering of rivers and streams, was mentioned on the board and that only added to the doubts. Had there been a change of posture? Or was it to be a "cosmetic" work, to be carried out for the World Cup? In that case, could it be that the stream would remain polluted and covered, and that the image on the board was picturing an artificial water mirror? Or, should the "prank" hypothesis put forward by the newspaper be the good one, who could have put that sign there anyway?

By Tuesday, the 28th, the sign was no longer in place. The newspapers Hoje em Dia and O Tempo announced that the municipal administration had opened an inquiry for violation of the City Code (fine: \$238.49) and that the Federal Police had begun to investigate the authors of the "fictitious project" for improper use of government logos. Such criminalization gave greater visibility to the issue. On social networks, hundreds of 
people expressed their support to the action. An online kitty was organized for crowdfunding the fine.

What the audacious investigators did not realize was that on Monday's newspaper report, Mr. Agnaldo Odorico, quoted as the owner of a bar located on the fateful corner, had given an important clue about the arrival of the board: "It was a City Hall truck that stopped and put it there", he claimed. On Wednesday, in a surprising move, an editorial by $\mathrm{O}$ Tempo resumed the controversy, somehow challenging the common sense by legitimizing the action for raising awareness among the local population as to the state of urban watercourses. It still referred to it, however, as a "joke".

From being perceived as a "prank" or a "joke" and despite the clear testimony of a local citizen, the board quickly became a police case, and now the perpetrators were being hunted down as criminals. In less than 72 hours, the restoration of the Leitão stream went from a real and thought-provoking possibility to something comparable to the gags of bad Sunday TV entertainment shows, and then to the truculence of the police pages. The stream and the possibility of transforming the urban environment were quickly obscured by the excitement of the search for the "authors."

In the witch-hunt, the initial target was Undió, an NGO that promotes artistic activities and workshops for young people in Padre Belchior Street. The director of the NGO had to reaffirm several times that the sign was not related to Undió. It is interesting that, even though suspicion fell on artists - whose vast repertoire includes performances, installations, urban interventions, site specifics or simply artworks - the action was still described in the press as a hoax.

Authorship, it is well known, is usually claimed by artists or by terrorists. And in the face of the disquieting absence of authors, couldn't that board simply be considered a political action? Politics should not be taken here in its institutional, partisan or electoral sense (which in Brazil, as elsewhere, usually involves and often comes down to the attack and demoralization of opponents), but in its full sense. Politics as referring to the collective construction of the polis - that is, of ordinary life in the city. Isn't politics after all a prerogative of any citizen? Or should it be the exclusive domain of candidates and public managers, legitimate representatives of the yearnings of the anonymous and appeased?

What the board made possible in the few hours during which it remained on the public promenade was the invention of a popular and informal micro-parliament dedicated to an exhaustive debate of the problems and the best solutions for the Leitão stream and for Padre Belchior Street, but also for any river in any city, from the point of view of the experiences and expectations of each citizen. From being a trivialized device in daily urban life, the public work sign became something like a high-definition screen, capturing the attention of a small, instant crowd and offering a glimpse of an unlikely and suddenly shareable future.

The growing presence of environmental issues in the media, in political speeches and in institutional propaganda has made the discussion about the global impacts of human actions and the climate crisis more recurring, although there have been very few results in adapting economic interests to a policy agenda that effectively includes nature and traditional knowledge in line with their preservation. Interestingly, little is said about the web of relationships between natural and cultural elements that should make up a balanced ecosystem at all scales, starting from the local level. The springs, streams, 
woods, birds, and trees just around the corner seem far and hopelessly doomed to disappear, while companies and governments shift responsibility for their actions and evoke the importance of every citizen in preserving the planet. The substitution of the word 'ecology' (the study of a place in which living organisms interact) for sustainability is symptomatic: the focus is no longer on the possible relationships between living beings, both human and non-human, and their environment, but on the possible continuity of a certain model. For green marketing campaigns, everything goes, as long as it is "sustainable".

Just as our coexistence with fish and birds is not on the agenda of the Ministry of Cities, cities are not on the agenda of the Ministry of Environment - much less on that of the Ministry of Fishery. And while the Ministry of Health cares for diseases, the idea of a city as a healthy and collectively produced ecosystem is very far away from state political agendas, at all levels.

The most elemental environmental changes should probably start with the recognition of the importance of water, but as long as streams and rivers continue to be channelled and covered with asphalt, no one will deal with them, because the consequences of such policies are made invisible. Within the logic of such inefficient and rudimentary systems that we insist, in the cities of the Global South, on calling "basic sanitation," nature is nothing more than a hindrance to progress, and the dysfunctions caused by its cycles will always be scrutinized by wilful technicians and solved by some new miraculous technology.

Belo Horizonte is a relatively new city, planned and built in the 1890s. Its planners never took into account the presence of its many waterways. They opted instead to rely on one single underground network that merged the city's wastewater and its storm flow, which was then directly released into its drainage system. Throughout the twentieth century, rivers and streams were channelled and covered, often with inauguration events and official celebrations.

In the year of 1963, two environmental occurrences marked the city: over 350 trees that lined the Afonso Pena Avenue were cut, while the Acaba Mundo stream was covered up with concrete. There were many protests against the felling of the trees, but almost none against the covering of the stream that once presented the townspeople with a waterfall within the Municipal Park.

The Leitão Stream was covered up in the 1970s, with the customary truculence of the military regime and its ideals of predatory modernization. Colossal developments at the time destroyed public gardens, cut down trees, and channelled and hid urban waters in order to ensure more car space. It is curious however that, after re-democratization, this remained the dominant ideal of municipal and state administrations, of all political stands.

While the city of Seoul now sees its Cheonggyecheon river flow back in the open, having suppressed more than 10 traffic lanes - without any prejudice to traffic - or while Medellín begins to transform 26 kilometres of expressways into a 424-hectare riparian park, Belo Horizonte passively watches as its main river, the Arrudas, turns into a steaming asphalt desert (sinisterly named "boulevard"), with more traffic lanes and no proven traffic improvement. 


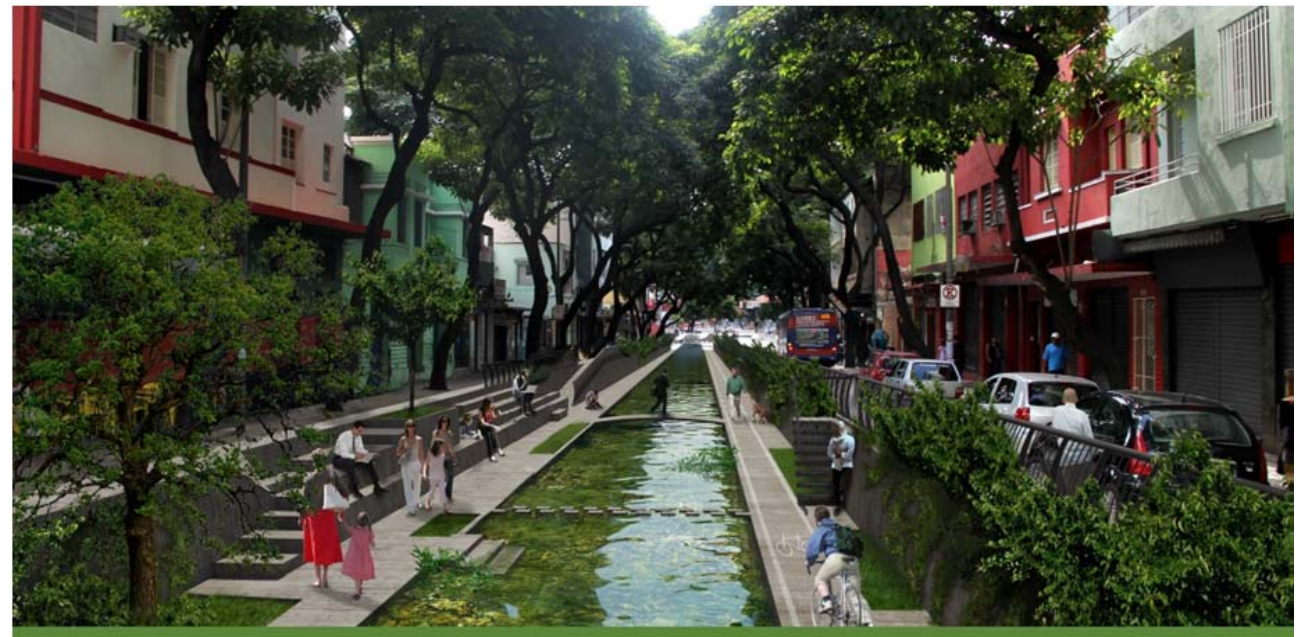

\section{RENATURALIZAÇÃO DO CÓRREGO DO LEITÃO}
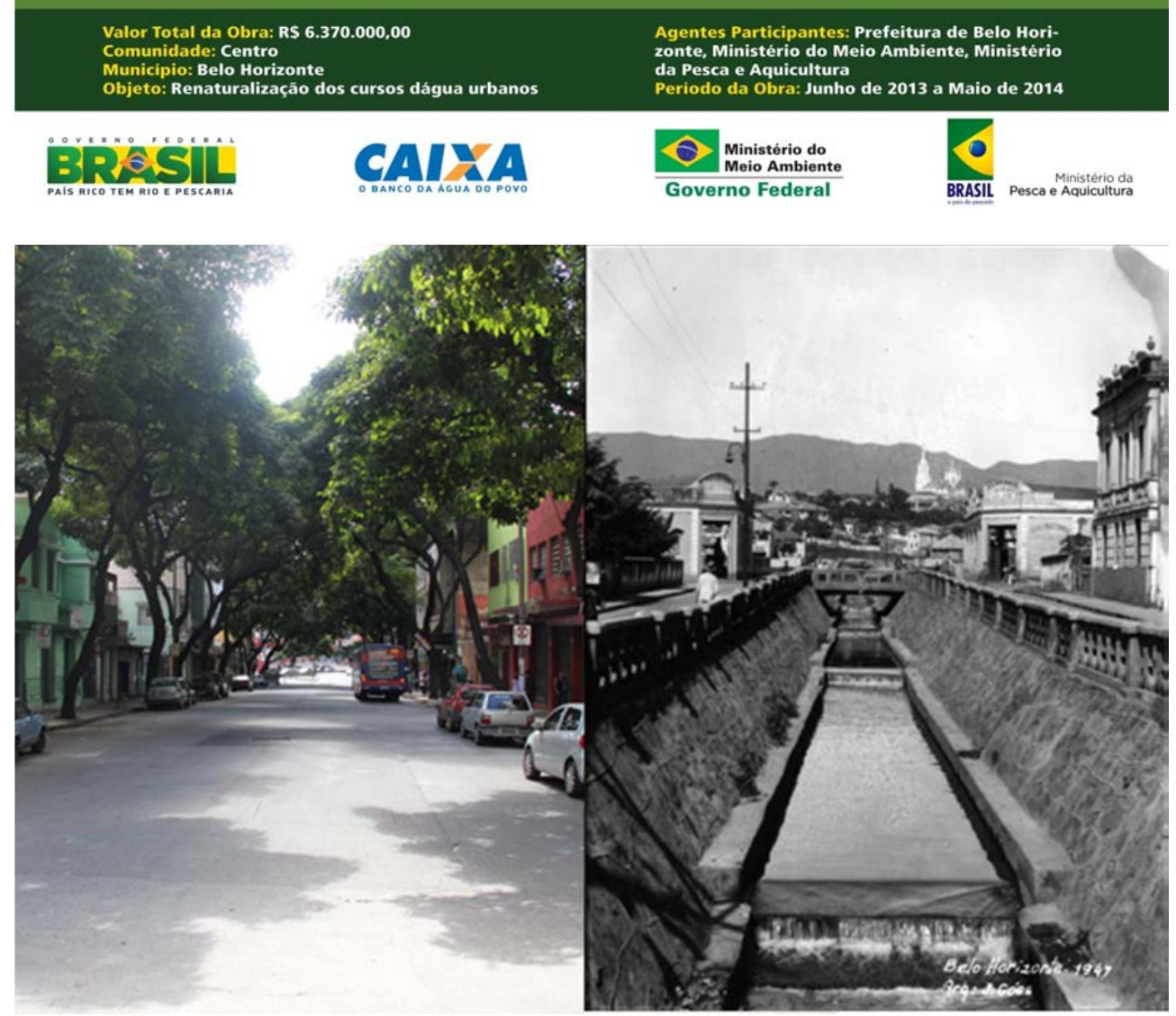

Figure 3 (top). The design proposal, as appeared on the sign, for the Restoration of the Leitão Stream. Figure 4 (bottom). A before-after picture of the site (the black and white picture on the right is dated 1949).

It is well known and documented that adding more car lanes or building overpasses is not a good solution for traffic problems - although it generates millionaire construction and maintenance contracts. Cities that were able to improve traffic and mobility did 
exactly the opposite: they reduced traffic lanes, eliminated parking spaces from the streets, widened sidewalks, taxed vehicle circulation, invested in public transport and bicycle infrastructure.

There is a joke that says that tackling traffic jams by widening roads is like fighting obesity by widening belts. It makes sense: the automobile is an ineffective and degrading means of urban mobility. It generates air and noise pollution, besides congestions. More than 4,000 people die each year in the city of São Paulo from diseases caused by air pollution. Automobiles are hugely responsible for such numbers. Another I,500 people die from traffic accidents. The car is a sort of epidemic that kills, in Brazil, more than cigarettes or HIV and tuberculosis combined. Moreover, public policies designed to preserve such a plague devastate waterways, trees, sidewalks, parks - and hopes. If printing government logos is a crime worthy of an investigation by the Federal Police, would it not be even more criminal to use these same logos in order to channel streams, build overpasses, expropriate entire communities, gentrify neighbourhoods, and condemn citizens to a desolate life? When none of the spheres of government can produce healthy and happy cities (with intercepted and treated sewage, collected and recycled waste, quiet, tree-lined streets, clean rivers and streams, smart mobility, and spaces built for people), isn't the anonymous act of injecting a little imagination into the official agenda a generous citizen contribution? And if public debate forums seem increasingly obsolete and politics is rapidly moving away from the public interest, should we all not be engaged in creating other ways of doing politics, bringing citizens closer together and imagining other future ecosystems?

Piseagrama is a non-profit editorial platform, dedicated do public spaces and common life in Brazil. The group is also engaged in several actions such as debates, publications and campaigns. www.piseagrama.org 